\title{
BIOCLIMATIC CONDITIONS UNDER DIFFERENT GROUND COVER TYPES IN THE GREATER ATHENS AREA, GREECE
}

\author{
A.P. KAMOUTSIS ${ }^{1}$ \\ A.S. MATSOUKIS ${ }^{1, *}$ \\ K.I. CHRONOPOULOS ${ }^{2}$
}

\author{
${ }^{1}$ Laboratory of General and Agricultural Meteorology \\ Agricultural University of Athens \\ 75, lera Odos Str., 11855 Athens, Greece \\ 'Laboratory of Physics, Agricultural University of Athens, \\ 75, lera Odos Str., 11855 Athens, Greece
}

Received: 05/04/13

Accepted: $28 / 04 / 13$
${ }^{*}$ to whom all correspondence should be addressed: e-mail: armatsoukis@aua.gr

\begin{abstract}
This research aims to investigate the bioclimatic conditions in different ground cover types in the greater Athens area, Greece: a major street with heavy traffic (MS), an adjacent pedestrian street (PS) with irrigated plants and an urban park. Four sites were selected: one in each of the streets, and two in the park, one of which is covered by irrigated plants (IPS) while the other is covered by non-irrigated plants (NIPS). Air temperature and relative humidity were monitored in each site during the periods of July-August and September-October of the years 2009 and 2010. These parameters were used for the calculation of the thermohygrometric index based on which bioclimatic conditions were evaluated. The "Hot" class prevailed at all sites during the July-August period while similar bioclimatic conditions detected at all environments with irrigated plants at the aforementioned period. During autumn, the "Comfortable" class prevailed at the PS and the urban park compared to the MS. The findings of our study could provide useful information for the design of outdoor spaces with irrigated vegetation as well as for the plantation and irrigation of plant species on city roads with heavy traffic.
\end{abstract}

KEYWORDS: thermohygrometric index, air temperature, relative humidity, major street, pedestrian street, urban park, irrigation, shading, Athens.

\section{INTRODUCTION}

The outdoor recreation in urban environments is of special importance (Toy and Yilmaz, 2010) and the use of green spaces by the visitors of the surrounding build up areas offers social and psychological benefits. Likewise, in the urban centers of Greece, mainly during the summer, the inhabitants like to spend their leisure time outdoors in advantageous comfortable environments.

Favorable bioclimatic conditions and lower temperatures are provided inside the parks and other green spaces located within urban centers compared to areas with various ground cover types of concrete and asphalt (Chow et al., 2011). For densely populated urban environments, green spaces with woody plant species provide the effect of shading and contribute to the reducing of air temperature ( $\mathrm{Ng}$ et al., 2012). Therefore, the creation of the aforementioned areas and the planting of vegetation in urban environments are supposed to be the main strategies for the mitigation of the urban warming controlling the Urban Heat Island effect (Yu and Hien, 2006).

The urban parks and other green spaces such as pedestrian streets, transitional areas between vegetated and built up areas are used as ideal areas for walking, sports and other cultural activities, especially during the warmest months and early autumn period in urban areas of Greece.

The thermal environment is influenced by the built environment and ground surface covering types (Matsoukis et al., 2012), by the evaporation of bare soil and the evapotranspiration of plants (Robitu 
et al., 2006; Larcher, 2003) and by the shading of trees and the occurrence of watery surfaces (Lin et al., 2010; Matsoukis et al., 2012).

The occurrence of trees in the urban environments causes a cooling effect during the warmest months (Leuzinger et al., 2010) influencing the local microclimate of the surrounding regions. In parks, where tree vegetation dominated, more advantageous biometeorological conditions were prevailed in comparison with other open green spaces, because of the high shading (Cohen et al., 2012). Considerable shading resulted in the increase of the duration of cool conditions. The benefits of this effect are noticed mainly during summer (Hwang et al., 2011) when the solar radiation presents its higher values.

This study aims to investigate the outdoor bioclimatic conditions of different ground cover types of an urban park in a densely populated municipality (Nea Smirni, NS) and of urban streets in the center of Athens.

\section{MATERIALS AND METHODS}

The field experiment was performed in two places of the greater Athens area in Greece. The first study area was the district Neo Pagrati (Figure 1a, b) located in the central part of Athens with commercial and residential housing blocks as well as narrow and wide streets. The second area (Figure 1a, c), Nea Smirni (NS), is located $3.5 \mathrm{Km}$ southwest of the aforementioned one, on the southern part of Athens. The Neo Pagrati area comprised two study sites which are characterized by different ground cover types (Table 1).

Table 1. Sites and ground cover types of the study area in the greater area of Athens, Greece

\begin{tabular}{|c|c|c|c|c|c|}
\hline \multirow[b]{2}{*}{ Area } & \multirow{2}{*}{$\begin{array}{l}\text { Locations } \\
\text { (site) }\end{array}$} & \multirow[b]{2}{*}{ Latitude } & \multirow[b]{2}{*}{ Longitude } & \multicolumn{2}{|c|}{ Ground cover type } \\
\hline & & & & $\begin{array}{l}\text { Ground } \\
\text { surface }\end{array}$ & Dominated vegetation \\
\hline \multirow[b]{2}{*}{$\begin{array}{l}\text { Neo } \\
\text { Pagrati }\end{array}$} & $\begin{array}{l}\text { Filolaou } \\
\text { Str. } \\
\text { (S1) }\end{array}$ & $37^{\circ} 57^{\prime} 58.3^{\prime \prime} \mathrm{N}$ & $23^{\circ} 45^{\prime} 09.7^{\prime \prime} \mathrm{E}$ & Asphalt & Morus alba L. \\
\hline & $\begin{array}{l}\text { Laskou } \\
\text { Str. } \\
\text { (S2) }\end{array}$ & $37^{\circ} 57^{\prime} 55.8^{\prime \prime} \mathrm{N}$ & $23^{\circ} 45^{\prime} 08.2^{\prime \prime} \mathrm{E}$ & Pavement & $\begin{array}{c}\text { Morus alba L., Pittosporum } \\
\text { chinense Dom., Ligustrum } \\
\text { japonicum Thunb., } \\
\text { Duranta plumieri Jacg. }\end{array}$ \\
\hline \multirow{2}{*}{$\begin{array}{l}\text { Nea } \\
\text { Smirni } \\
\text { Urban } \\
\text { Park }\end{array}$} & $\begin{array}{l}\text { IPS } \\
\text { (S3) } \\
\text { (S4) }\end{array}$ & $\begin{array}{l}37^{\circ} 57^{\prime} 01.6^{\prime \prime} \mathrm{N} \\
37^{\circ} 57^{\prime} 00.9^{\prime \prime} \mathrm{N}\end{array}$ & $\begin{array}{l}23^{\circ} 42^{\prime} 57.2^{\prime \prime} \mathrm{E} \\
23^{\circ} 43^{\prime} 01.3^{\prime \prime} \mathrm{E}\end{array}$ & Grass & $\begin{array}{l}\text { Pinus halepensis Mill., } \\
\text { Phoenix dactylifera L. }\end{array}$ \\
\hline & $\begin{array}{l}\text { NIPS } \\
\text { (S5) } \\
\text { (S6) }\end{array}$ & $\begin{array}{l}37^{\circ} 57^{\prime} 04.8^{\prime \prime} \mathrm{N} \\
37^{\circ} 57^{\prime} 03.0^{\prime \prime} \mathrm{N}\end{array}$ & $\begin{array}{l}23^{\circ} 43^{\prime} 0.6^{\prime \prime} \mathrm{E} \\
23^{\circ} 42^{\prime} 55.9^{\prime \prime} \mathrm{E}\end{array}$ & Bare soil & $\begin{array}{c}\text { Pinus halepensis Mill., } \\
\text { Eucalyptus sp. }\end{array}$ \\
\hline
\end{tabular}

The first site S1 was located in Filolaou street, a wide major street (MS) with northeast (NE) southwest (SW) orientation, which is characterized by heavy traffic during the whole period of the year. The second site S2 was located in the Laskou street, one of the parallels of the aforementioned road with the same orientation (Figure 1a, b). This is a pedestrian narrow street (PS) covered by irrigated trees and woody shrubs as well as by structural materials.

The second study area NS (Figure 1a, c) has a central urban park which occupies an area of approximately 5 ha and comprised two studied ground cover types (Table 1). The first type is covered by irrigated plant species (IPS) and includes small watery surfaces and a fountain. This type comprised the sites S3 and S4. The second type is covered by non-irrigated plant species (NIPS) and included the sites S5 and S6 as shown in Figure 1a, c.

In each study site of the two examined areas, air temperature and relative humidity data were monitored simultaneously every $15 \mathrm{~min}$ by sensors with data loggers (Hobo type Pro, H08-032-08, USA, accuracy $\pm 0.2{ }^{\circ} \mathrm{C}$ at $25^{\circ} \mathrm{C}$ for air temperature and $\pm 3.0 \%$ for relative humidity over $50-60{ }^{\circ} \mathrm{C}$ ) during the period of 2009 and 2010. The aforementioned instruments, before the installation in the measurement locations, were calibrated in the laboratory against reference sensors and tested for a period of five days. Additionally, every six months, the instruments were tested in situ against reference sensors. These tests revealed no shift errors for any of the sensors. The instruments were 
enclosed in appropriate shelters screened from precipitation and direct solar radiation and mounded under selected trees $1.5 \mathrm{~m}$ above ground surface. The form of the shelters allowed acceptable air ventilation. The aforementioned measuring height was selected for comparison reasons, taking into account that the meteorological shelter is located at the height of $1.5 \mathrm{~m}$ approximately above the ground surface (Flocas, 1997). It is noted that the most rapid fluctuations of meteorological parameters take place within the lowest few meters above ground surface (W.M.O., 1981).

Air temperature and relative humidity averages were calculated on an hourly basis for each study site, separately for the years 2009 and 2010 . These values were used for the calculation of the average hourly values of a simple index (Toy et al., 2007), the thermohygrometric index (THI), at each study site, according to the following equation:

$\mathrm{THI}\left({ }^{0} \mathrm{C}\right)=\mathrm{t}-[(0.55-0.0055 \mathrm{f})(\mathrm{t}-14.5)]$

where $\mathrm{t}=$ =air temperature $\left({ }^{\circ} \mathrm{C}\right)$ and $\mathrm{f}=$ relative humidity $(\%)$. This index was selected because it is practical and easily applicable (Chronopoulos et al., 2012) in urban environments in Greece (Kamoutsis et al., 2007; Matsoukis et al., 2009; Chronopoulou-Sereli and Chronopoulos, 2011) and is based on data of environmental parameters which exist in the majority of the meteorological stations of our country. The use of more complex indices $(\mathrm{MCl})$, like the Physiological Equivalent Temperature (PET) or Universal Thermal Climate Index (UTCI), which are based on the energy balance of the human body (Nastos and Matzarakis, 2012; Matzarakis and Nastos, 2010) requires more meteorological parameters (e.g. global solar radiation, wind speed etc.). This, along with the absence of appropriate instruments for their measurement in the majority of the meteorological stations of our country synthesize a restrictive factor of $\mathrm{MCl}$ use (Chronopoulos et al., 2012) because the comparison of the results with these from other regions in Greece will not be possible. In the case of the NS urban park, average THI values were calculated for each ground cover type of the respective examined sites.

The mean value of average temperature in Athens was $18.2{ }^{\circ} \mathrm{C}$ according to the nearby meteorological station of Agricultural University of Athens, from 1991 to 2011. The mean temperature values during summer and winter were $27.3^{\circ} \mathrm{C}$ and $10.2{ }^{\circ} \mathrm{C}$, respectively, while the mean temperature during autumn was higher by $3.0^{\circ} \mathrm{C}$ compared to the respective value during spring. Also, it has been reported that between the transitional seasons, autumn is warmer than spring (Mariolopoulos, 1938). Therefore, in this paper we choose to present autumn, and specifically its warmest months, September and October, as the warmest transitional season of the year. Also, we present July and August as the warmest months of the absolute warmest period of the year, summer, while we do not take into account the winter season. It is noted that in the aforementioned examined months, the visitors prefer green spaces than other ground cover types.

Latitude (E)

(b)

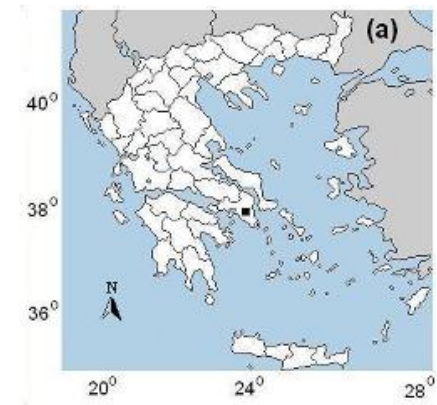

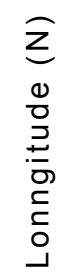

(c)

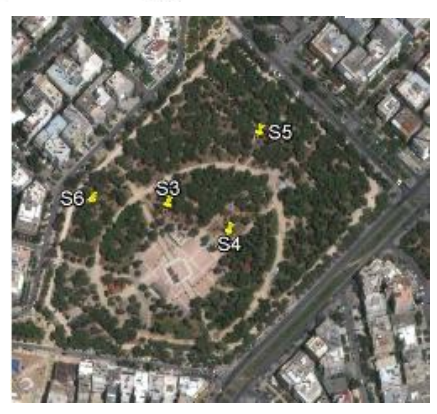

Figure 1. Study region (square with black color) in Attica, Greece (a) and study sites of examined ground cover types* in (b) Neo Pagrati (S1, S2) and (c) urban park of Nea Smirni (S3, S4, S5, S6) in the greater area of Athens, Greece

(Source: Google Earth 2013, on 23-62012).

*The ground cover types were not changed after the field measurements 
Average THI values were used for the evaluation of bioclimatic conditions (Table 2) as modified from Toy et al. (2007). It has been reported that the discomfort levels of a precursor index, the Thom's index, were predicted in the Greater Athens Area using artificial neural network models during the hot season of the year (Vouterakos et al., 2012). The relative frequencies of THI values for both study years were calculated on an hourly basis during the examined periods.

Table 2. Relation of bioclimatic conditions with thermohygrometric index (THI)

\begin{tabular}{lc}
\hline Bioclimatic conditions & THI $\left({ }^{\circ} \mathbf{C}\right)$ \\
\hline Cool & +13.0 to +14.9 \\
\hline Comfortable & +15.0 to +19.9 \\
\hline Hot & +20.0 to +26.4 \\
\hline Very Hot & +26.5 to +29.9 \\
\hline
\end{tabular}

\section{RESULTS AND DISCUSSION}

Bioclimatic conditions as expressed by the relative frequencies of different THI classes in each hour for the examined periods at the ground cover types of the studied locations are presented in Figures 2 and 3. The classes "Hot" and "Very Hot" were detected during the hottest period (July-August) at all study sites, with "Hot" prevailing (relative frequency $>86.0 \%$ ) during almost the whole day (Figure 2a, b, c, d).

Noticeable percentages of the THI values $(33.1 \%$ at MS and $23.5 \%$ at NIPS) were classed as "Very Hot" from 10:00 to 19:00 h (Figure 2a, c). Small percentages (approximately 5.0\%) of these values were detected in both PS (Figure 2b) and IPS (Figure 2d). Also, a small percentage of the THI values (totally 5.4\%) occupied the "Comfortable" class in IPS site from 04:00 h to 06:00 h (Figure 2d).

Disadvantageous biometeorological conditions prevailed during the hottest period of the year at MS and NIPS sites, because of the greater percentages of "Very Hot" class in comparison with the PS and IPS sites. It is noted that MS is characterized by NE-SW orientation. Cohen et al. (2012) reported that unfavorable thermal conditions were provided in the east-west oriented streets during the summer. Also, the lack of irrigation at the MS and the NIPS sites causes a negative impact on their thermal environment in relation to the PS and IPS sites.

During the September-October period the classes "Comfortable", "Hot" and "Very Hot" were detected at all study sites. The "Comfortable" class prevailed at the PS (>52.2\%), NIPS $(>49.3 \%)$ and IPS (> $52.1 \%$ ) sites (Figure 3b, c, d, respectively) while the "Hot" class prevailed (> 56.0\%) at the MS site. At this site, a smaller percentage (42.2\%) of THI values occupied the "Comfortable" class during the whole day (Figure 3a) while noticeable percentages of the THI values were classed as "Hot" at the PS (47.7\%), NIPS (48.4\%) and IPS (46.3\%) sites (Figure 3b, c, d). Additionally, small percentages of THI values were classed as "Very Hot" (Figure $3 a, b, c, d$ ) at all study sites (from $0.1 \%$ at PS to $1.3 \%$ at MS) and "Cool" at IPS (1.4\%) and NIPS (1.1\%) sites (Figure 3c, d).

It seems that similar and more favorable bioclimatic conditions prevailed in both areas of PS and IPS sites (smaller percentages of THI values as "Very Hot" in the summer and greater percentages of these values as "Comfortable" in the autumn), in relation to MS and NIPS sites, during the whole studied period. This fact could be attributed mainly to the irrigation of the trees and other plant species in these areas. It is noted that watery surfaces are located near the IPS site. Regarding the role of irrigation, and water in general, on local microclimate, the findings of our study are in accordance with the study of Horbert et al. (1988) who mentioned that more advantageous bioclimatic conditions prevailed in the heavily irrigated green areas (e.g. National Garden) in comparison with natural wooded areas (e.g. slope of Lycabettus hill), in Athens, Greece during the May-September period. Hassaan and Mahmoud (2011) indicated the beneficial effects of urban parks on bioclimatic conditions and pointed out the combined impacts of trees and watery surfaces on the shading effect and evaporative cooling.

Also, Leuzinger et al. (2010) have reported lower foliage temperature values in park trees than the respective values of street trees in Basel, Switzerland. 
(a)

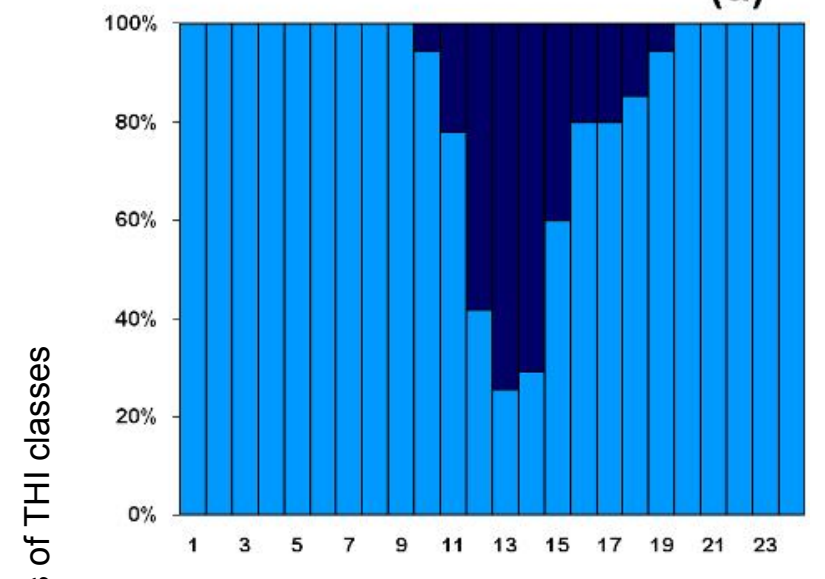

(c)

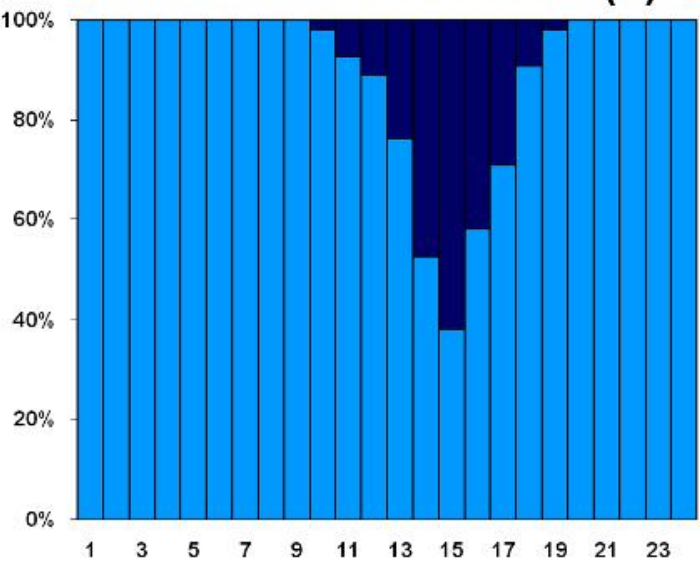

(b)

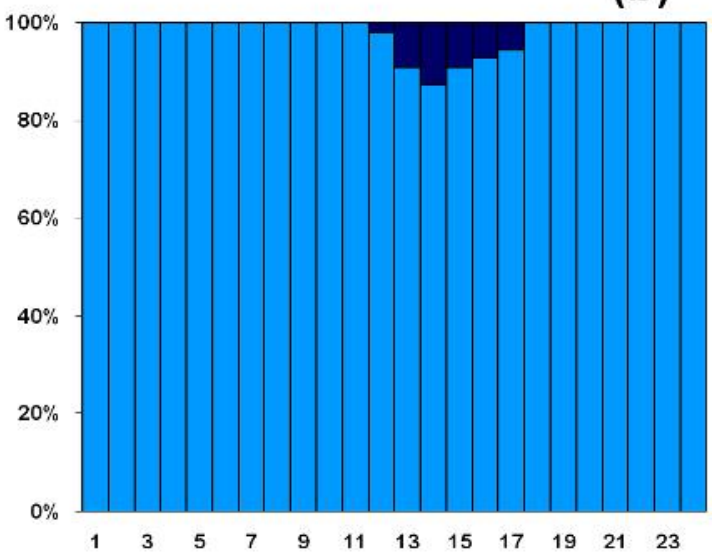

(d)

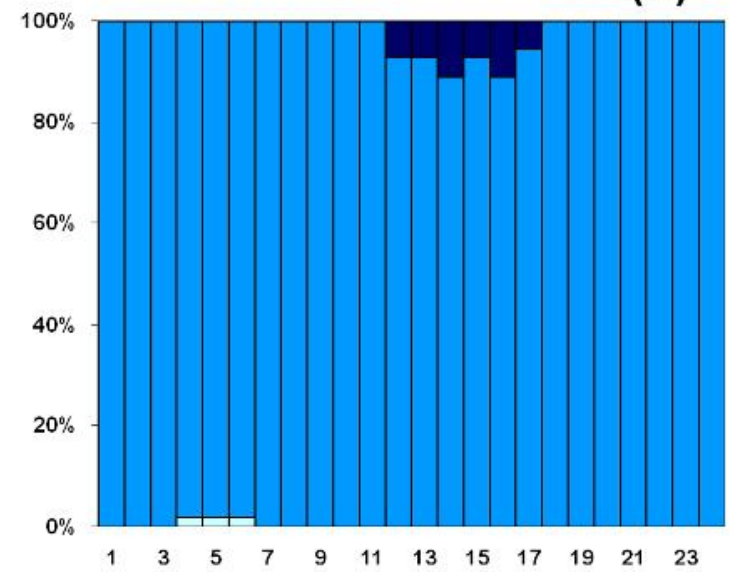

Time (LST)

$\square$ Comfortable $\square$ Hot $\square$ Very Hot

Figure 2. Relative frequencies of different classes of thermohygrometric index (THI) values on hourly basis in (a) the major (MS) and (b) pedestrian (PS) streets of Neo Pagrati, in the environments with (c) non-irrigated (NIPS) and (d) irrigated (IPS) plant species of Nea Smirni urban park in the greater area of Athens, Greece, during the July-August period of 2009 and 2010.

(LST: Local Standard Time $=$ Greenwich Meridian time $+2 \mathrm{~h}$ )

\section{CONCLUSIONS}

This study focuses on the investigation of bioclimatic conditions in different places of the greater Athens area, Greece: a major street with heavy traffic, an adjacent pedestrian street with irrigated plant species and different ground cover types of an urban park with irrigated and non-irrigated plant species. The major conclusions are highlighted below:

- During the summer the "Hot" class prevailed at all study sites of the examined areas.

- Similar bioclimatic conditions during the summer were noticed between the two environments with irrigated plants (pedestrian street and site with irrigated plant species inside the park).

- The "Comfortable" class prevailed at the pedestrian street and at both ground cover types inside the urban park (irrigated and non-irrigated) while the "Hot" class prevailed at the major street during the autumn.

The findings of our study could be used for outdoor space design emphasizing the increase of irrigated vegetation in open spaces, such as urban parks and pedestrian streets, especially in the 
hottest months of the year, as well as for the design of plantation of irrigated shrubs and trees on city roads with heavy traffic.

(a)

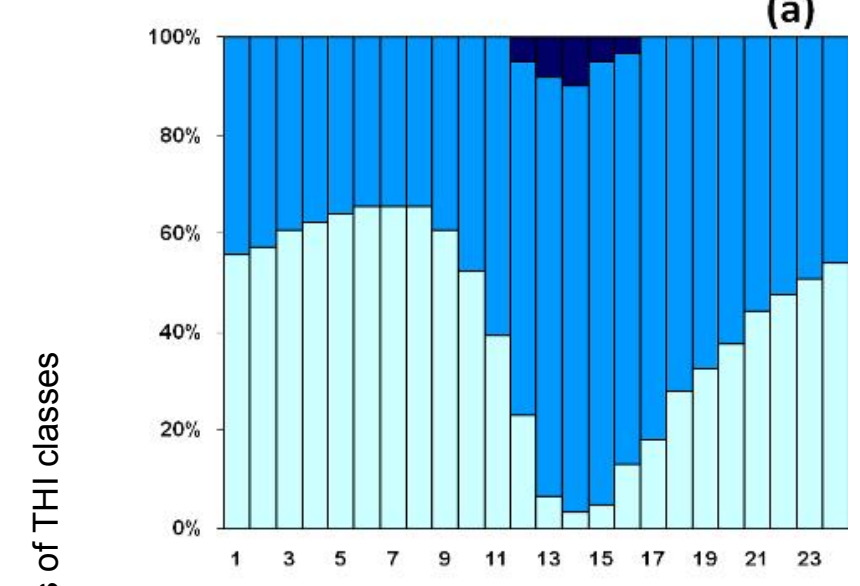

(c)

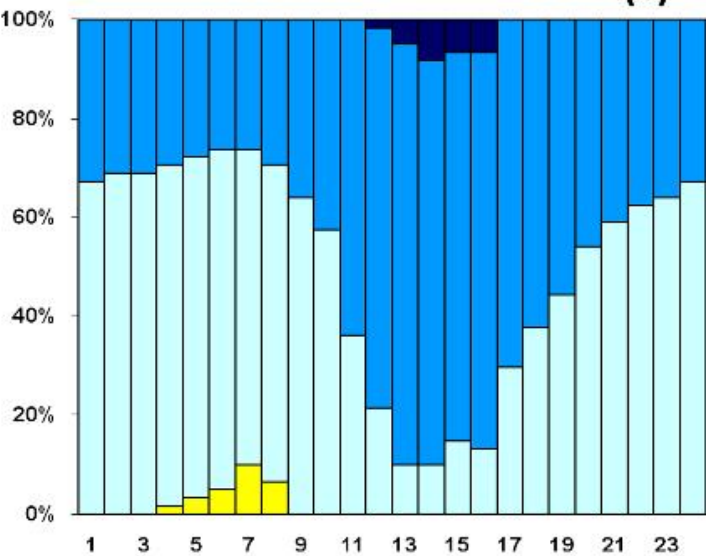

(b)

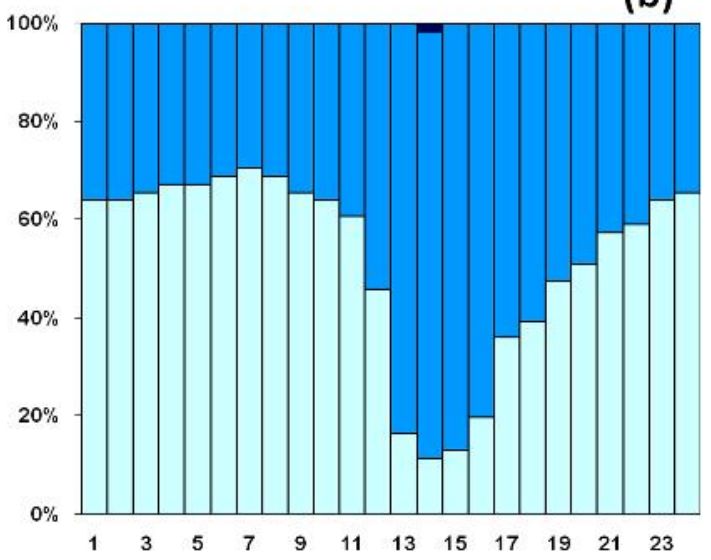

(d)

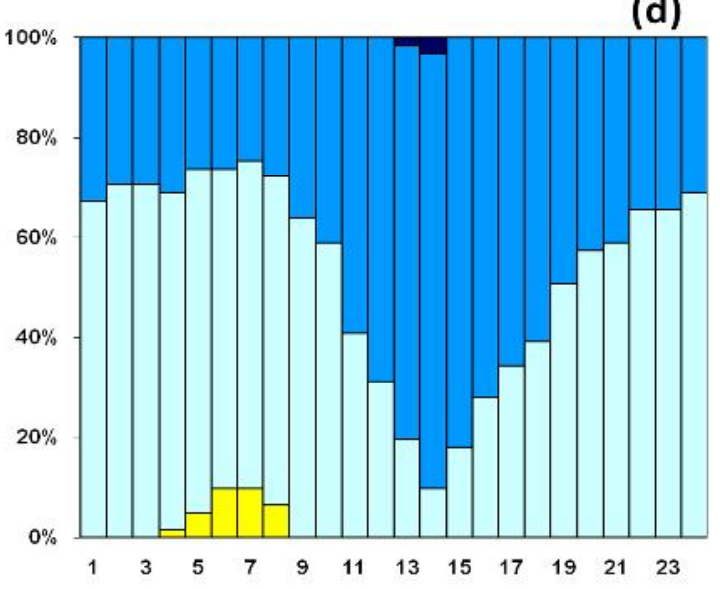

Time (LST)

Cool $\square$ Comfortable $\square$ Hot $\square$ Very Hot

Figure 3. Relative frequencies of different classes of thermohygrometric index (THI) values on hourly basis in (a) the major (MS) and (b) pedestrian (PS) streets of Neo Pagrati, in the environments with (c) non-irrigated (NIPS) and (d) irrigated (IPS) plant species of Nea Smirni urban park in the greater area of Athens, Greece, during the September-October period of 2009 and 2010.

(LST: Local Standard Time $=$ Greenwich Meridian time $+2 \mathrm{~h}$ )

\section{REFERENCES}

Chow W.T.L., Poe R.L., Martin C.A. and Brazil,A.G. (2011), Observing and modeling the nocturnal park cool island of an arid city: horizontal and vertical impacts, Theor. Appl. Climatol., 103, 197-211.

Chronopoulos K., Kamoutsis A., Matsoukis A. and Manoli A. (2012), An artificial neural network model application for the estimation of thermal comfort conditions in mountainous regions, Greece, Atmósfera, 25, 171-181.

Chronopoulou-Sereli A. and Chronopoulos J. (2011), Biometeorology-bioclimatology, applications to the configuration of outdoor species, First edition, Ziti Publications, Thessaloniki, Greece (in Greek).

Cohen P., Potchter O. and Matzarakis A. (2012), Daily and seasonal climatic conditions of green urban spaces in the Mediterranean climate and their impact on human comfort, Building and Environment, 51, 285-295.

Flocas A. (1997), Lessons in Meteorology and Climatology, Second Edition, Zitis Publications, Thessaloniki, Greece (in Greek). 
Hassaan A. and Mahmoud A. (2011), Analysis of the microclimatic and human comfort conditions in an urban park in hot and arid regions, Building and Environment, 46, 2641-2656.

Horbert M., Kirchgeorg A., Chronopoulou-Sereli A. and Chronopoulos J. (1988), Impact of green on the urban atmosphere in Athens, Kernforschungsanlage Jülich $\mathrm{GmbH}$, Scientific Series of the International Bureau, Berlin, Germany.

Hwang R.-L., Lin T.-P. and Matzarakis A. (2011), Seasonal effects of urban street shading on long term thermal comfort, Building and Environment, 46, 863-870.

Kamoutsis A., Matsoukis A., Charalampopoulos I. and Chronopoulou-Sereli A. (2007), Biometeorological conditions in mountainous communities and adjacent urban center in Greece by the use of indices: The case study of mountainous Nafpaktia district, In: Developments in Tourism Climatology, 3rd International Workshop on Climate, Tourism and Recreation, Matzarakis A., de Freitas C.R. and Scott D. (eds.), Commission on Climate, Tourism and Recreation International Society of Biometeorology, Freiburg, Germany.

Larcher W. (2003), Physiological Plant Ecology, Ecophysiology and Stress Physiology of Functional Groups, Fourth Edition, Springer Verlag Berlin Heidelberg New York.

Leuzinger S., Vogt R. and Körner C. (2010), Tree surface temperature in an urban environment, Agric. For. Meteorol., 150, 56-62.

Lin T.-P., Matzarakis A. and Hwang R.-L. (2010), Shading effect on long-term outdoor thermal comfort, Building and Environment, 45, 213-221.

Mariolopoulos H. (1938), The climate of Greece, Athens, Greece (in Greek).

Matsoukis A., Kamoutsis A. and Chronopoulou-Sereli A. (2009), Air temperature and thermal comfort conditions in mountainous and urban regions, Int. J. Sus. Dev. Plann., 4, 357-363.

Matsoukis A., Kamoutsis A., Bollas A. and Chronopoulou-Sereli A. (2012), Biometeorological conditions in the urban park of Nea Smirni in the greater region of Athens, Greece during Summer, In: Advances in Meteorology, Climatology and Atmospheric Physics, Helmis C.G. and Nastos P.T. (Eds.), Springer Atmospheric Sciences, Springer Heidelberg New York Dordrecht London.

Matzarakis A. and Nastos P.T. (2010), Human-Biometeorological assessment of heatwaves in Athens, Theor. Appl. Climatol., 105, 99-106.

Nastos P.T. and Matzarakis A. (2012), The effect of air temperature and human thermal indices on mortality in Athens, Theor. Appl. Climatol., 108, 591-599.

$\mathrm{Ng}$ E., Chen L., Wang Y. and Yuan C. (2012), A study on the cooling effects of greening in a high-density city: An experience from Hong Kong, Building and Environment, 47, 256-271.

Robitu M., Musy M., Inard C. and Groleau D. (2006), Modeling the influence of vegetation and water pond on urban microclimate, Solar Energy, 80, 435-447.

Toy S., Yilmaz S. and Yilmaz H. (2007), Determination of bioclimatic comfort in three different land uses in the city of Erzurum, Turkey, Building and Environment, 42, 1315-1318.

Toy S. and Yilmaz S. (2010), Thermal sensation of people performing recreational activities in shadowy environment: a case study from Turkey, Theor. Appl. Climatol., 101, 329-343.

Vouterakos P.A., Moustris K.P., Bartzokas A., Ziomas I.C., Nastos P.T. and Paliatsos A.G. (2012), Forecasting the discomfort levels within the greater Athens area, Greece using artificial neural networks and multiple criteria analysis, Theor. Appl. Climatol., 110, 329-343.

W.M.O. (1981), Guide to agricultural meteorological practices, WMO-No. 134, Second Edition, Secretariat of the World Meteorological Organization, Geneva, Switzerland.

Yu T. and Hien W.N. (2006), Thermal benefits of city parks, Energy and Buildings, 38, 105-120. 